\title{
Impact of Instructor Teaching Style and Content Course on Mathematics Anxiety of Preservice Teachers
}

\section{Suriza Van der Sandt \& Steve O'Brien}

\begin{abstract}
Integrative-STEM methodologies entail integrating multiple disciplines with active design-centric teaching and learning methods. If math anxiety is prevalent, for teachers or students, then both the level of integration and design thinking may be limited. This quantitative study of 160 preservice teachers investigated how math anxiety was impacted by (a) a required math content course, (b) instructor teaching style, and (c) academic and disciplinary major. Significance analyses included $t$-tests, nonparametric tests, and effect sizes. Two teaching styles were compared: a direct teaching style and a more active, problem-based teaching style. The problem-based teaching style was shown to have substantial beneficial impact on math anxiety.
\end{abstract}

Keywords: STEM education, mathematics anxiety, teaching styles

Previous works have discussed the acronym STEM (science, technology, engineering, and mathematics) and $\mathrm{K}-12$ STEM education in general (Sanders, 2009). Sanders (2009) and Virginia Tech (2017) faculty have discussed and defined the term integrative-STEM education. Additionally, the National Academy of Engineering and the National Research Council (Honey, Pearson, \& Schweingruber, 2009) produced a detailed report describing many aspects of integrative-STEM (I-STEM) methods. This report addressed definitions of ISTEM, reviewed research related to I-STEM education, and discussed practice and implementation of I-STEM. Researchers have also created frameworks to guide I-STEM teaching. Wells (2016) proposed the PIRPOSAL model (which stands for Problem Identification, Ideation, Research, Potential Solutions, Optimization, Solution Evaluation, Alterations, and Learned Outcomes) that has clear ties to problem-based learning (PBL) via the central importance of questioning. Several $\mathrm{K}-12$ school districts have chosen to add an $A$ (arts), engaging via STEAM education, peaking the interest of art educators (Liao, 2016).

In the authors' view, if the key attributes of I-STEM teaching and learning could be compressed into two concepts, those would be (a) integrative and (b) include substantial design-centric problem- or project-based learning. These two aspects are not independent but are linked because the design-centric theme (the $T$ and $E$ components) provides rich contexts for the integration of STEM and non-STEM content areas. The problem- or project-based teaching and learning methods in I-STEM activities are design-centric with teachers guiding a student- 
centered environment where students, typically working in small groups, are designing solutions to problems, resulting in artifacts representing the solution (a physical artifact or modified process). There are a variety of items that can compromise the quality of I-STEM teaching. For example, questioning techniques are clearly important and have a central place in Wells' (2016) PIRPOSAL model. Another potential factor is mathematics anxiety. The literature indicates that high math anxiety can have several detrimental impacts in the classroom. Each of the two fundamental aspects of I-STEM methods previously listed could be detrimentally impacted. For example, if teachers have high math anxiety, then I-STEM activities may be limited in both the amount and quality of integrated math or may not encourage quantitative design decisions. Additionally, students with high math anxiety may also purposefully shy away from quantitative-based processes.

The authors could find no reported work on the impact of PBL teaching styles on math anxiety of in- or pre-service teachers. This is potentially of fundamental importance to PBL-centric I-STEM classes. For example, if PBL methods can beneficially impact math anxiety of preservice teachers, then perhaps PBL-centric I-STEM methods will also have a beneficial impact on $\mathrm{K}$ 12 students and teachers. In this work, a quantitative measure of math anxiety is completed for early preservice teachers before and after a required math (for educators) content course. Independent variables studied are: (a) a required content math course, (b) teaching style (active or PBL vs. direct), and (c) academic and disciplinary majors.

\section{Math Anxiety}

\section{Literature Review}

Mathematics anxiety can be defined as an intense feeling of anxiety about one's ability to understand and do math, a specific event such as a math test, or certain situations involving math. According to Brown, Westenskow, and Moyer-Packenham (2011), math anxiety reflects how an individual views his or her own ability to interact with mathematics.

More broadly, mathematics anxiety can be defined as the stress of learning and participating in the mathematics classroom or in situations that require mathematics (Richardson \& Suinn, 1972) or as a fearful avoidance of mathematical situations (Wadlington \& Wadlington, 2008). Math anxiety is the result of a student's previous negative or embarrassing experiences with math or a math teacher. Math anxiety is not a learning disability, but it does interfere with an individual's ability to learn math (Wadlington \& Wadlington, 2008) and inhibits students' ability to understand and participate in mathematics. Isiksal, Curran, Koc, and Askun (2009) also found a significant negative correlation between math anxiety and self-concept scores. These experiences can leave students with the belief that they are deficient in math. Ashcraft (2002) believes that students with math anxiety will avoid situations requiring math, which 
could "result in less competency, exposure and math practice, leaving students more anxious" (p. 173). Brady and Bowd (2005) found that nearly $40 \%$ of the education students in their study reported math as their least favorite subject.

Math anxiety can develop early in elementary school (Harper \& Daane, 1998). Jackson and Leffingwell (1999) reported that some students had their first negative experiences as early as third or fourth grade. Geist (2010) believes that

Instead of helping children develop fluency at computation and become more efficient at problem solving, these policies [current educational policies] have produced students that rely more on rote memorization and have increased the level of anxiety in young children by making mathematics a high-risk activity. This tends to produce more adults with 'math anxiety' and discouraged children who understand the concept but work a little slower. (p. 25)

Finlayson (2014) believes that teacher behavior is a prime factor contributing to math anxiety.

Math anxiety of preservice teachers and impact on teaching and learning. A significantly larger percent of preservice teachers report experiencing higher levels of math anxiety than other undergraduate university students (Harper \& Daane, 1998; Hembree, 1990). Frank (1990) found that many future teachers shared many of the same math beliefs held by students enrolled in math anxiety clinics. There is a particular concern in the case of elementary school teachers because a disproportionately large percentage of them experience significant levels of mathematics anxiety (Buhlman \& Young, 1982; Trujillo \& Hadfield, 1999). Kelly and Tomhave (1985) found that prospective elementary school teachers scored higher on anxiety rating scales than any other group in the large group of college freshmen they tested. Based on this research, it is not surprising that a considerable proportion of students entering preservice teacher training have negative beliefs and attitudes about mathematics (Uusimaki \& Nason, 2004). Brown et al. (2011) also believe that teachers who do not enjoy math and who have negative feelings and less ability in mathematics would have difficulty teaching math or teaching math well.

The vast majority of elementary education majors are female and exhibit the highest level of math anxiety of any major (Hembree, 1990). Beilock, Gunderson, Ramirez, and Levine (2010) found that "teachers with high math anxiety seem to be specifically affecting girls' math achievement - and doing so by influencing girls' gender-related beliefs about who is good at math" ( $p$. 1862). Geist (2010) found that "girls tend to feel less confident about their answers on tests and often express doubt about their performance" in math, and over time, girls' "assessment of their enjoyment of mathematics falls much more 
drastically than" boys' (p. 26). Moreover, studies have shown that teachers with high levels of math anxiety tend to transfer this anxiety to their students (Finlayson, 2014; Vinson, 2001). Some researchers found that such teachers are viewed as unsympathetic (Cornell, 1999) and insensitive (Jackson \& Leffingwell, 1999), and Brady and Bowd (2005) found that such teachers were viewed as hostile and uncaring by their students. Furthermore, these students had memories of struggling with particular concepts and experiencing embarrassment in front of peers. Jackson and Leffingwell (1999) report that girls were ridiculed more often than boys and received less assistance from such teachers. Swetman, Munday, and Windham (1993) indicate that teachers with high measures of math anxiety spend less time planning mathematics lessons and use math instruction time for nonmath-related activities.

Additionally, Teague and Austin-Martin (1981) found that a teachers' attitude toward mathematics may affect not only the students' values and attitudes toward mathematics but also that these attitudes may affect the effectiveness of the teaching itself. Brown et al. (2011) established in their study that nearly $21 \%$ of the preservice teachers with anxiety about mathematics had negative mathematics teaching experiences with students in their field-based practicum.

Much of the research focusing on math anxiety and preservice-teacher training links math anxiety to teacher efficacy. Swars, Daane, and Giesen (2006) as well as Bursal and Paznokas (2006) found negative correlations between math anxiety and math efficacy beliefs, whereas Gresham (2008) associates low math anxiety with high levels of math efficacy. Math anxiety is also negatively correlated with confidence to teach math (Brady \& Bowd, 2005). A commonality among these studies is that the participants were all in a methodology class (e.g., Brown, Westenskow, \& Moyer-Packenham, 2011; Finlayson, 2014; Gresham, 2007) and near the end of their preservice training (Brady \& Bowd, 2005; Isiksal, Curran, Koc, \& Askun, 2009). We are in agreement with Brown et al. (2011) and Finlayson (2014) who acknowledge a weak mathematical background as a factor contributing to math anxiety. Therefore, we decided to investigate the level of math anxiety as they enter their training as teachers. Additionally, we decided to study the impact of a required math content course taken early in their program.

Another limitation in the current literature is the near exclusive focus on math anxiety among elementary major preservice teachers (Brown et al., 2011) with no consideration of other education majors (e.g., early childhood, special education, or deaf and hard of hearing majors) or academic major (e.g., math major). Zientek, Thompson. and Yetkiner (2010) believe that "it may be of value to investigate whether preservice teachers' mathematics anxiety levels are most associated with areas of certification preparation (e.g., early childhood, $\mathrm{K}-$ 8 ) or by the courses in which the teachers are enrolled" (p. 430). This investigation includes these other education major populations with additional 
variables of disciplinary major and instructor's teaching style. By reference, Finlayson's (2014) study, 40\% of the study participants identified "teaching style" as a cause for their math anxiety.

\section{Teaching Style}

Problem-based learning. Based on the work of Barrows (Barrows, 2002; Hmelo-Silver \& Barrows, 2006), Walker and Leary (2009) define a PBL teaching style in which (a) "ill-structured problems are presented" (p. 13), (b) "a student centered approach in which students determine what they need to learn" is used, (c) "teachers act as a facilitators or tutors in the learning process," and (d) "authenticity forms the basis" in the selection of "problems [that] are inherently cross-disciplinary" (p. 14). In the work of Barrows (2002) and Hmelo-Silver and Barrows (2006), the importance of group work is included as a fifth element.

Researchers have found that PBL or PBL-like activities have had substantial positive impacts on student learning. PBL was first widely reported in the field of medical education. Meta-analysis of PBL have been reported both in the medical field (Strobel \& van Barneveld, 2009) and outside the medical field (Walker \& Leary, 2009). Strobel and van Barneveld (2009) found meaningful effect sizes for (a) "knowledge assessment," (b) "performance or skill-oriented" assessment, and (c) "non-performance or skill-oriented" attributes, including "satisfaction" and "successful assignment of first choice of [medical] residency" positions (p. 52). The meta-analysis of Walker and Leary (2009) included the addition of nonmedical field studies and variables of problem types, disciplines, and assessment levels. This meta-analysis described a large number of factors with statistical validity, too many to review here; however, it is interesting to note that the problem type "design problem" had the largest effect size (0.74), which may bode well for I-STEM methods.

Direct teaching. Mercer, Lane, Jordan, Allsop, and Eisele (1996) define explicit or direct instruction as "instruction in which the teacher serves as the [primary] provider of knowledge" and explanations, presenting "skills and concepts . . . in a clear and direct fashion that promotes student mastery" ( $p$. 227). Additionally, Burton (1998) observed that college-level engineering lectures generally take a "'teaching is telling" approach (p. 158).

\section{Research Questions}

We designed this study to answer the following questions:

1. What is the level of math anxiety with which prospective grade school teachers enter their teacher-training program?

2. What effect does a mathematics content course have on the level of math anxiety experienced by prospective teachers?

3. What effect does the lecturer's teaching style have on the level of math 
anxiety?

4. Do different education or disciplinary majors have substantially different math anxiety?

\section{Population}

\section{Methodology}

The population consisted of 160 preservice teachers. Participants were primarily freshmen at a public liberal arts college situated on the East Coast. The mean quantitative SAT scores for education majors at the institution has varied between 600 and 630 over the past 8 years. The population in this study was made up of the following education majors: elementary (ELEM, $n=79$ ), early childhood (EACH, $n=36$ ), deaf-and-hard of hearing (DEAF, $n=23$ ), and special education (SPED, $n=22$ ). EACH students would be certified to teach K3 , ELEM students would be certified to teach K-6, and DEAF and SPED students would be certified to teach $\mathrm{K}-12$. A second, disciplinary major is required for all education majors. The 160 preservice teachers in this study also spanned the following disciplinary majors: art (AR, $n=2)$, English (ENG, $n=$ 40), history (HIS, $n=16$ ), math (MATH, $n=2$ ), music (MU, $n=3$ ), psychology (PSY, $n=44$ ), sociology (SO, $n=12$ ), Spanish (SPA, $n=6$ ), women and gender studies (WG, $n=11$ ), and integrative STEM (I-STEM, $n=18$ ). Four students were double disciplinary majors (for example, WG and HIS or WG and SPA), one student was a business major, and another student was an international studies major. MATH majors are certified to teach math for $\mathrm{K}-12$, and approximately $90 \%$ of I-STEM majors complete the state-required coursework for middle school endorsements for both mathematics and science. Additionally, approximately $50 \%$ of I-STEM majors complete coursework for K-12 endorsement for technology and engineering (T\&E) education.

\section{Data Collection and Math Anxiety Instrument}

Data were collected for two sequential semesters from students attending a compulsory math content course for elementary school teachers. The content courses were taught by only two instructors: 93 students attended Instructor A's class, and 67 students attended Instructor B's class. At the beginning and end of their course, participants were asked to voluntarily complete the RevisedMathematics Anxiety Survey (R-MANX), created by Bursal and Paznokas (2006), enabling paired statistical analyses. Only paired data were utilized, measuring predominately the impact of the course (and teaching style). The RMANX instrument contains 30 items to which students respond on a Likert scale from 1 (no anxiety) to 5 (high anxiety). Possible scores range from 30-150 with higher scores indicating higher math anxiety. The survey asked the student to define their level of math anxiety when dealing with daily situations and their own coursework. Cronbach's alpha for the R-MANX was calculated as 0.90 (Bursal \& Paznokas, 2006). 


\section{Math Content Course Overview}

The compulsory content course is designed for future teachers and is taught by mathematics education faculty. The course explores elementary school mathematics from an advanced viewpoint. Preservice teachers study patterns, numeration, mathematical systems, real numbers, and number theory. Students are required to reason mathematically, solve problems, and communicate mathematics effectively at different levels of formality, using a variety of representations of mathematical concepts and procedures. The two instructors used the same textbook and covered the same chapters. The format for both classes was in-person instruction for approximately 14 weeks. Classes were held twice per week, and each session was 80 minutes long.

\section{Teaching Style Determination}

One of the researchers visited each of the instructors' classrooms on several occasions during the year to collect data (at least three times per semester).

During classroom observations, the researcher took observation notes about the classroom discourse and teaching style demonstrated by each instructor and also collected copies of the syllabi and assessments. Hence, this study was an ex post facto study design.

Instructor A, with 8 years college-level teaching experience, used a variety of physical materials and models (e.g., Cuisenaire rods, pattern blocks, tangrams, and different base blocks). Students were encouraged, through activities based on exploration, to demonstrate a willingness and ability to solve various types of mathematical problems using appropriate strategies. Students were required to explain their answers, reasoning, and problem-solving methods in class, on homework, and on assessments. Students often left their seats to collect manipulatives, work with other students on solving problems, and make brief presentations based on their explorations. Students were often encouraged to work in pairs or groups to explore, discover, and present solutions. The majority of class sessions contained one of more of the five key PBL elements presented earlier in the literature review section. It was evident that Instructor A followed a more problem-based, inquiry-driven teaching style and is referred to as a problem-based teaching style (PBT).

Instructor B, with more than 30 years of college level teaching experience, followed nearly the same procedure at each observation. The instructor presented some example (or examples) on the board, showed the steps in solving the problem (or problems), allowed time for questions, and then assigned homework (problems similar to the example or examples presented in class) to be completed in class and at home. The classroom discourse was instructor driven and blackboard and textbook dominated; no use of manipulatives was observed. Students stayed in their seats, took notes, and worked individually on assigned problems. The teacher set the pace of the discourse, with a clear focus 
on computation and skill in both teaching and in assessment events. From the observation notes, it is evident that Instructor B followed a primarily direct teaching style, with very little evidence of PBL. In this study, Teacher B is referred to as having a direct teaching style (Direct T).

\section{Results}

Analyses were completed only for teacher candidates that successfully completed surveys both before and after the math content course, primarily assessing the impact of the course (including teaching style). To test for normality, the Kolmogorov-Smirnov tests were utilized (with $p>0.05$ ). If paired data are normally distributed, paired $t$-tests were utilized. If data was nonparametric, Wilcoxon Signed Rank Tests were utilized for statistical significance $(p<0.050)$. For practical significances, we utilized effect sizes $(d$ values 0 to $0.2,0.2$ to 0.5 , and $d>0.8$ for small, medium, and large practical significance, respectively).

\section{Entering Math Anxiety and Effect of Content Course}

To answer our first two research questions, we determined the range, mean $(\mu)$, standard deviation $\left(\sigma_{\bar{x}}\right), p$-value (statistical significance), and $d$-value (practical significance) of math anxiety for the 160 preservice teachers before and after the content course. Results are given in Table 1.

Table 1

Math Anxiety Levels Before and After Content Course

\begin{tabular}{|c|c|c|c|c|c|c|c|c|c|c|c|}
\hline & \multicolumn{5}{|c|}{$\begin{array}{l}\text { Entering preservice } \\
\text { training }\end{array}$} & \multicolumn{4}{|c|}{$\begin{array}{l}\text { After content } \\
\text { course }\end{array}$} & \multirow{2}{*}{$\begin{array}{c}p- \\
\text { value }\end{array}$} & \multirow{2}{*}{$\begin{array}{c}d- \\
\text { value }\end{array}$} \\
\hline & $N$ & & ange & $\mu$ & $\sigma_{\bar{x}}$ & & ange & $\mu$ & $\sigma_{\bar{x}}$ & & \\
\hline $\begin{array}{l}\text { Pre- } \\
\text { service } \\
\text { teachers }\end{array}$ & 160 & 68 & 128 & 82.91 & 13.94 & 49 & 112 & 78.48 & 12.39 & 0.000 & 0.34 \\
\hline
\end{tabular}

Table 1 indicates that students entered their training with an average $\mathrm{R}$ MANX score of 82.9 and exited the course with an average score of 78.5, a 4.4point $(5.3 \%)$ decrease. The standard deviation decreased from 13.9 to 12.4 after the course. The range in anxiety scores was large. For example, before the course, the lower quartile (low anxiety) spanned a narrow 5-point range, and the upper quartile extended over a much larger 36-point range (see Figure 1). After the course, the lower quartile increased to a 21-point range, and the upper quartile span decreased to a 26.5-point range. Additionally, the minimum score dropped 19 points, and the maximum score had decreased by 16 points. This 
freshmen-level content course had a statistically significant impact $(p<0.05)$ and a medium practical effect size (0.34).

Entering Training

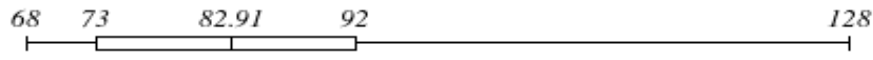

After Content Course
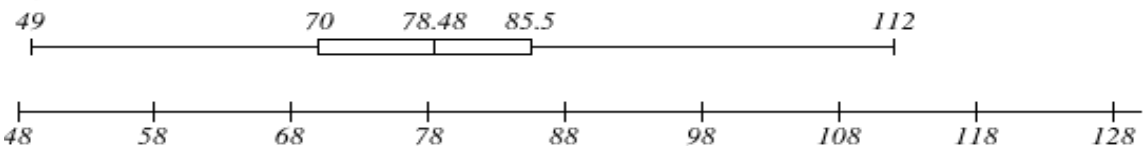

Figure 1. Math anxiety data distribution.

\section{Teaching Style}

To address our third research question, the impact of teaching style, we compared Instructor A's (PBT) students to Instructor B's (Direct T) students (see Table 2). Only if there was a statistical significant difference $(p<0.050)$ did we investigate effect sizes (see Table 2). The mean score for the Direct $\mathrm{T}$ students increased from 75.1 to 76.6 (about $2 \%$ ). In contrast, the scores for the PBT students lowered from 88.5 to 79.9 (nearly 10\%). Attending a problembased class led to a statistically and practically significant decrease in math anxiety, but attending a Direct $\mathrm{T}$ class did not.

Table 2

Impact of Lecturer's Teaching Style on Math Anxiety Levels

\begin{tabular}{|c|c|c|c|c|c|c|c|c|c|c|c|c|}
\hline & \multirow[b]{2}{*}{$n$} & \multicolumn{4}{|c|}{$\begin{array}{l}\text { Entering preservice } \\
\text { training }\end{array}$} & \multicolumn{4}{|c|}{ After content course } & \multicolumn{3}{|c|}{ Impact } \\
\hline & & & nge & $\mu$ & $\sigma_{\bar{x}}$ & & nge & $\mu$ & $\sigma_{\bar{x}}$ & Points & $\begin{array}{c}p- \\
\text { value }\end{array}$ & $\begin{array}{c}d \text { - } \\
\text { value }\end{array}$ \\
\hline PBT & 93 & 68 & 128 & 88.54 & 12.37 & 53 & 112 & 79.85 & 12.03 & -8.69 & 0.000 & 0.71 \\
\hline Direct $T$ & 67 & 48 & 107 & 75.09 & 12.61 & 49 & 106 & 76.58 & 12.80 & +1.49 & 0.335 & - \\
\hline
\end{tabular}

A comparison of the mean anxiety score before the content course indicates that the students in the PBT classes started with higher anxiety than students in the Direct T classes. A Mann-Whitney Test comparing the Direct T and PBT students before the course indicated that there was a statistically significant difference $(p=0.000)$. This is not surprising because students were not prefiltered into classes. The reductions shown in Table 2 for the PBT population may be due to the PBT population starting with substantially higher anxiety. That is, it may be easier to decrease anxiety in high anxiety students, no matter 
the teaching style. This question can be addressed by assessing the impact of the course (and teaching style) on (a) the high anxiety students in Direct T courses and (b) the low anxiety students in PBT courses. The median value of 82 for the total population was used to divide students into two groups: high and low anxiety populations. These analyses showed that (a) the high anxiety students in the Direct T courses $(n=17)$ showed no statistically significant changes $(p=$ 0.394 via a Wilcoxon Signed Rank Test) and (b) the low anxiety students in the PBT courses $(n=36)$ showed a 5-point decrease in the mean which was statistically significant $(p<0.0001$ via a paired $t$-test with a large effect size, $d=$ 1.03). These analyses indicate that the PBT teaching style does have a large impact for high and low anxiety students. In contrast, the direct teaching style had no significant impact on either high or low anxiety students.

\section{Disciplinary Majors}

Our expectation was that nonmath majors may start with a higher level of math anxiety, due to a possible lower level of content knowledge, and be impacted more positively by the content course as they gain knowledge to teach math. We defined math teaching (MATH-t) majors as both I-STEM $(n=18)$ and MATH $(n=2)$ majors because both will be certified to teach higher levels of math. Our expectation was that MATH-t majors would start with a lower level math anxiety and that the content course would reduce nonmath majors' math anxiety more than math majors. The analysis of math anxiety by math and nonmath majors is presented in Table 3.

Table 3

Impact of Lecturer's Teaching Style on Math Anxiety Levels of Math and Nonmath Majors

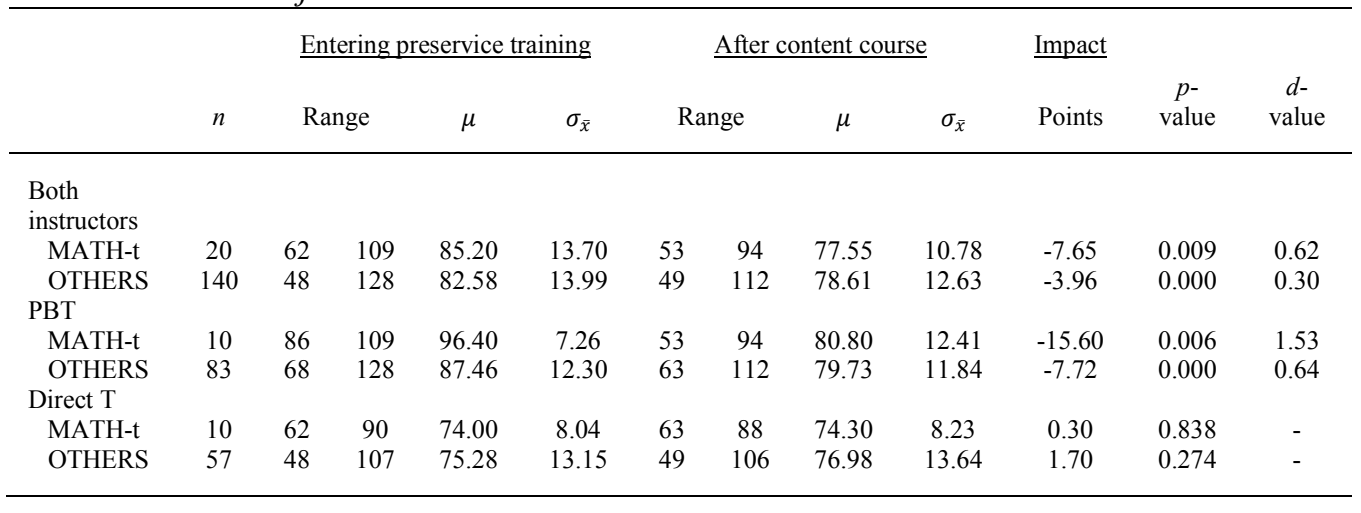

The results for the total population (both instructors) show that both math and nonmath majors benefitted from attending the content course because both were statistically significant. The 20 math majors showed the greatest decrease in 
math anxiety, 7.7-points (nearly 9\%). The practical significance was medium for the MATH-t majors and small for the nonmath students.

More significant differences by disciplinary major were apparent when accounting for teaching style. Instructor B (Direct T) had no statistically significant impact on either MATH-t or nonmath students. By contrast, Instructor A (PBT) had a large positive impact on MATH-t and nonmath majors, which was statistically significant with large to medium effect sizes.

\section{Education Majors}

The analysis of math anxiety by different education majors is presented in Table 4. A one-way ANOVA test, using the total population, resulted in a $p$ value of 0.344 indicating that the four groups were not statistically significantly different before the content course. Using the total population, all four education major groups showed decreases on anxiety of 4 to 6 points, three of which were statistically significant with medium practical significance. (The fourth group, DEAF, was close to significant with $p=0.057$.)

More significant differences by education major were apparent when separating teaching style. All education majors in the PBT courses had statistically significant decreases in anxiety, which had medium to large effect sizes. The students in the Direct T courses had a substantially smaller impact, with predominately increases of anxiety. Only one subgroup (ELEM) had a statistically significant difference $(p=0.049)$, an increase in anxiety of 2.65 points.

The SPED group did appear to be unique in that anxiety reductions were observed for both Direct T and PBT classes (but with only the PBT group being statistically significant). 
Table 4

Impact of Lecturer's Teaching Style on Math Anxiety Levels of Different Education Majors

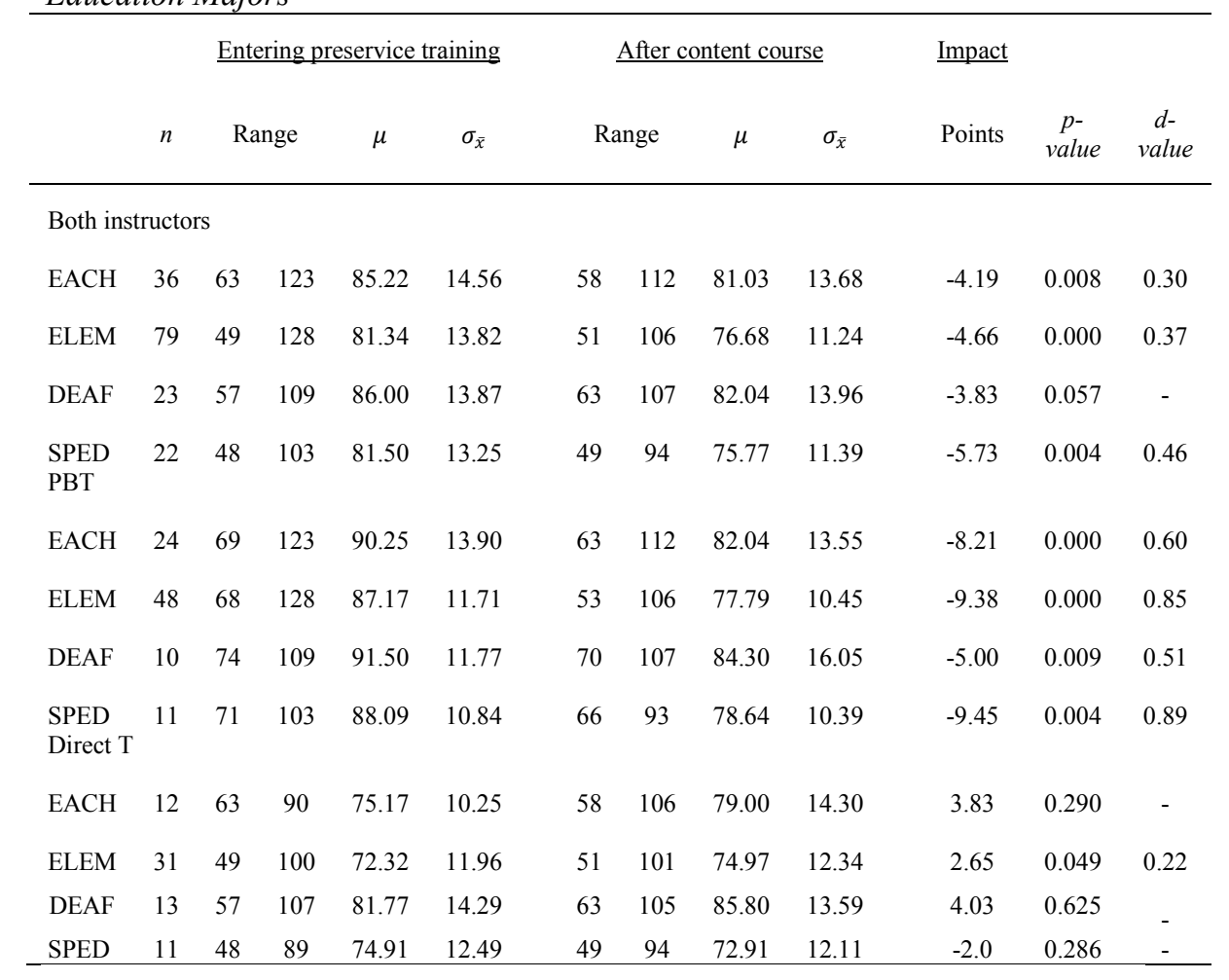

\section{Summary}

Students entering their training had an R-MANX math anxiety level of 82.9. A required math content course (for educators) was useful in reducing math anxiety. Reductions in math anxiety were observed across education and disciplinary majors. Teaching style had a large beneficial impact on math anxiety, with a PBL style exhibiting statistically significant decreases and medium to large practical differences. In contrast, a direct teaching style had either no impact or a detrimental impact on anxiety. All subgroups were beneficially impacted by a PBL teaching style, but only SPED majors were beneficially impacted by a direct teaching style (not statistically significant). 


\section{Discussion}

We agree with Mercer et al. (1996) that a single instructional method is seldom effective for all students; however, in this study, a PBL-centric teaching style profoundly decreased math anxiety in an education contextualized math content course. This has substantial implications for both the implementation and impact of I-STEM methods as well as how we train T\&E teachers. In general, our T\&E teacher preparation programs have limited math, science, and engineering (each having important math contexts). This lower emphasis on math likely results in higher math anxious $T \& E$ teachers and limited implementation of PBL methods, and it certainly limits how much engineering (vs. technology) can be effectively addressed in classes. Litowitz (2014) found that $75 \%$ of our T\&E teacher preparation programs required only lower level math courses. Additionally, Litowitz (2014) found only one program with a required contextualized (engineering) math course. A lower emphasis on math has also been evident in our certified teachers. When investigating familiarity with the grade level of mathematics standards, Flowers and Rose (2014) found that T\&E teachers were (a) only accurate $40 \%$ of the time and (b) off by two or more grade levels $30 \%$ of the time. Additionally, mathematics is also not represented substantially in field research. Of the 97 papers published in this journal from spring 2007 through spring 2016, only seven had the word mathematics in the title. Strimel and Grubbs (2016) also discussed several of these observations, as well as other observations, when suggesting a larger emphasis on engineering in the field. Because I-STEM teaching utilizes designcentric PBL methods, this study indicates that I-STEM activities may lower math anxiety and therefore increase mathematical skills in both $\mathrm{K}-12$ students and preservice $\mathrm{T} \& \mathrm{E}$ teachers. If $\mathrm{T} \& \mathrm{E}$ teacher preparation programs generally required more education-centric or contextualized math courses (especially utilizing a PBL teaching style), then I-STEM (or Engineering) methods might be more effectively be implemented. Burghardt, Hecht, Russo, Lauckhardt, and Hacker (2010) also suggests that mathematically integrated PBL-centric ISTEM methods be modeled in preservice T\&E teacher programs. ${ }^{1}$

\section{Future Work}

Questions that remain include inquiries on the longevity of this impact as well as extending the study to specific preservice or in-service elementary or secondary teachers in T\&E or STEM and extending the study to other institutions.

\footnotetext{
${ }^{1}$ It should be noted that technology education has worked on integrated curricula math projects (LaPorte \& Sanders, 1993; Satchwell \& Loepp, 2002).
} 


\section{References}

Ashcraft, M. H. (2002). Math anxiety: Personal, educational, and cognitive consequences. Current Directions in Psychological Sciences, 11(5), 181185. doi:10.1111/1467-8721.00196

Bandura, A. (1986). Social foundations of thought and action: A social cognitive theory. Englewood Cliffs, NJ: Prentice-Hall.

Barrows, H. (2002). Is it truly possible to have such a thing as dPBL? Distance Education, 23(1), 119-122. doi:10.1080/01587910220124026

Beilock, S. L., Gunderson, E. A., Ramirez, G., \& Levine, S. C. (2010). Female teachers' math anxiety affects girls' math achievement. Proceedings of the National Academy of Sciences of the United States of America, 107(5) 1860-1863. doi:10.1073/pnas.0910967107

Brady, P., \& Bowd, A. (2005). Mathematics anxiety, prior experience and confidence to teach mathematics among pre-service education students. Teachers and Teaching: Theory and Practice, 11(1), 37-46. doi:10.1080/1354060042000337084

Brown, A. B., Westenskow, A., \& Moyer-Packenham, P. S. (2011). Elementary pre-service teachers: Can they experience mathematics teaching anxiety without having mathematics anxiety? Issues in the Undergraduate Mathematics Preparation of School Teachers: The Journal, 5. Retrieved from http://www.k12prep.math.ttu.edu/journal/5.attributes/brown01/article.pdf

Buhlman, B. J., \& Young, D. M. (1982). On the transmission of mathematics anxiety. Arithmetic Teacher, 30(3), 55-56.

Burghardt, M. D., Hecht, D., Russo, M., Lauckhardt, J., \& Hacker, M. (2010). A study of mathematics infusion in middle school technology education classes. Journal of Technology Education, 22(1), 58-74. doi:10.21061/jte.v22i1.a.4

Bursal, M., \& Paznokas, L. (2006). Mathematics anxiety and preservice elementary teachers' confidence to teach mathematics and science. School Science and Mathematics, 106(4), 173-180. doi:10.1111/j.19498594.2006.tb18073.x

Burton, L. (1998). Undergraduate engineering education: Teaching, learning, assessing-A symbiosis. Engineering Science and Education Journal, 7(4), 158-160. doi:10.1049/esej:19980404

Cornell, C. (1999). "I hate math! I couldn't learn it, and I can't teach it!" Childhood Education, 75(4), 225-231. doi:10.1080/00094056.1999.10522022

Finlayson, M. (2014). Addressing math anxiety in the classroom. Improving Schools, 17(1), 99-115. doi:10.1177/1365480214521457

Flowers, J., \& Rose, M. A. (2014). Mathematics in technology \& engineering education: Judgments of grade-level appropriateness. Journal of Technology Education, 25(2), 18-34. doi:10.21061/jte.v25i2.a.2 
Frank, M. L. (1990). What myths about mathematics are held and conveyed by teachers? Arithmetic Teacher, 37(5), 10-12.

Geist, E. (2010). The anti-anxiety curriculum: Combating math anxiety in the classroom. Journal of Instructional Psychology, 37(1), 24-31.

Gibson, S., \& Dembo, M. H. (1984). Teacher efficacy: A construct validation. Journal of Educational Psychology, 76(4), 569-582. doi:10.1037/00220663.76.4.569

Gresham, G. (2007). A study of mathematics anxiety in pre-service teachers. Early Childhood Education Journal, 35(2), 181-188. doi:10.1007/s10643007-0174-7

Gresham, G. (2008). Mathematics anxiety and mathematics teacher efficacy in elementary pre-service teachers. Teaching Education, 19(3), 171-184. doi:10.1080/10476210802250133

Harper, N. W., \& Daane, C. J. (1998). Causes and reductions of math anxiety in preservice elementary teachers. Action in Teacher Education, 19(4), 29-38. doi:10.1080/01626620.1998.10462889

Hembree, R. (1990). The nature, effects, and relief of mathematics anxiety. Journal for Research in Mathematics Education, 21(1), 33-46. doi:10.2307/749455

Hmelo-Silver, C. E., \& Barrows, H. S. (2006). Goals and strategies of a problem-based learning facilitator. The Interdisciplinary Journal of Problem-Based Learning, 1(1), 21-39. doi:10.7771/1541-5015.1004

Honey, M., Pearson, G., \& Schweingruber, H. (Eds.). (2009). STEM integration in K-12 education: Status, prospects, and an agenda for research. Washington DC: National Academies Press. doi:10.17226/18612

Isiksal, M., Curran, J. M., Koc, Y., \& Askun, C. S. (2009). Mathematics anxiety and mathematical self-concept: Considerations in preparing elementaryschool teachers. Social Behavior and Personality, 37(5), 631-644. doi:10.2224/sbp.2009.37.5.631

Jackson, C. D., \& Leffingwell, R. J. (1999). The role of instructors in creating math anxiety in students from Kindergarten through college. Mathematics Teacher, 92(7), 583-586.

Kelly, W. P., \& Tomhave, W. K. (1985). A study of math anxiety/math avoidance in preservice elementary teachers. Arithmetic Teacher, 32(5), 5153.

LaPorte, J., \& Sanders, M. (1993). The T/S/M Integration Project: Integrating technology, science, and mathematics in the middle school. The Technology Teacher, 52(6), 17-21.

Liao, C. (2016). From interdisciplinary to transdisciplinary: An arts-integrated approach to STEAM education. Art Education, 69(6), 44-49. doi:10.1080/00043125.2016.1224873

Litowitz, L. S. (2014). A curricular analysis of undergraduate technology \& engineering teacher preparation programs in the United States. Journal of 
Technology Education, 25(2), 73-84. doi:10.21061/jte.v25i2.a.5

Mercer, C. D., Lane, H. B., Jordan, L., Allsopp, D. H., \& Eisele, M. R. (1996). Empowering teachers and students with instructional choices in inclusive settings. Remedial and Special Education, 17(4), 226-236. doi:10.1177/074193259601700405

Richardson, F. C., \& Suinn, R. M. (1972). The Mathematics Anxiety Rating Scale: Psychometric data. Journal of Counseling Psychology, 19(6), 551554. doi: $10.1037 / \mathrm{h} 0033456$

Sanders, M. (2009). STEM, STEM education, STEMmania. The Technology Teacher, 68(4), 20-26.

Satchwell, R. E., \& Loepp. F. L. (2002). Designing and implementing an integrated mathematics, science, and technology curriculum for the middle school. Journal of Industrial Teacher Education, 39(3), 41-66.

Strimel. G., \& Grubbs, M. E. (2016). Positioning technology and engineering education as a key force in STEM education. Journal of Technology Education, 27(2), 21-36. doi:10.21061/jte.v27i2.a.2

Strobel, J., \& van Barneveld, A. (2009). When is PBL more effective? A metasynthesis of meta-analyses comparing PBL to conventional classrooms. Interdisciplinary Journal of Problem-Based Learning, 3(1), 44-58. doi:10.7771/1541-5015.1046

Swars, S. L., Daane, C. J., \& Giesen, J. (2006). Mathematics anxiety and mathematics teacher efficacy: What is the relationship in elementary preservice teachers? School Science and Mathematics, 106(7), 306-315. doi:10.1111/j.1949-8594.2006.tb17921.x

Swetman, B., Munday, R., \& Windham, R. (1993). Math-anxious teachers: Breaking the cycle. College Student Journal, 22(4), 421-427.

Teague, P. T., \& Austin-Martin, G. (1981, February). Effects of a mathematics methods course on prospective elementary school teachers' math attitudes, math anxiety, and teaching performance. Paper presented at the annual meeting of the Southwest Educational Research Association, Dallas, TX.

Trujillo, K. M., \& Hadfield, O. D. (1999). Tracing the roots of mathematics anxiety through in-depth interviews with preservice elementary teachers. College Student Journal, 33(2), 219-232.

Uusimaki, L., \& Nason, R. (2004). Causes underlying pre-service teachers' negative beliefs and anxieties about mathematics. In Proceedings of the 26th Conference of the International Group for the Psychology of Mathematics Education (Vol. 4, pp. 369-376). Retrieved from https://www.emis.de/proceedings/PME28/RR/RR141_Uusimaki.pdf

Vinson, B. M. (2001). A comparison of preservice teachers' mathematics anxiety before and after a methods class emphasizing manipulatives. Early Childhood Education Journal, 29(2), 89-94. doi:10.1023/A:1012568711257 
Virginia Tech. (2017). Integrative STEM education. Retrieved from http://www.soe.vt.edu/istemed/

Wadlington, E., \& Wadlington, P. L. (2008). Helping students with mathematical disabilities to succeed. Preventing School Failure, 53(1), 2-7. doi:10.3200/PSFL.53.1.2-7

Walker, A., \& Leary, H. (2009). A problem based learning meta analysis: Differences across problem types, implementation types, disciplines, and assessment levels. Interdisciplinary Journal of Problem-Based Learning, 3(1), 12-43. doi:10.7771/1541-5015.1061

Wells, J. G. (2016). PIRPOSAL model of integrative STEM education: Conceptual and pedagogical framework for classroom implementation. Technology and Engineering Teacher, 75(6), 12-19.

Zientek, L. R., Thompson, B., \& Yetkiner, Z. E. (2010). Characterizing the mathematics anxiety literature using confidence intervals as a literature review mechanism. Journal of Educational Research, 103(6), 424-438. doi:10.1080/00220670903383093

\begin{abstract}
About the Authors
Suriza Van der Sandt (vandersa@tcnj.edu) is Associate Professor in the Department of Mathematics and Statistics at The College of New Jersey.

Steve O'Brien (obriens@tcnj.edu) is Associate Professor and Chair of the Department of Technological Studies at The College of New Jersey.
\end{abstract}

